\title{
Efficacy of Albendazole and Short-Course Prednisolone Treatment in Children with One or Two Ring-Enhancing Lesions of Neurocysticercosis: A Randomized Controlled Trial
}

\author{
Swain PK ${ }^{1}$, Thapalial A ${ }^{2}$, Das RN ${ }^{3}$, Dhaliwal MS $^{4}$, Subedi K ${ }^{5}$ \\ ${ }^{1}$ Dr. Pradipta Kumar Swain, M.D. Paediatrics, Associate Professor, ${ }^{2}$ Dr. Anna Thaplial, M.D. Paediatrics, DHPM, FCCP, Prof. \& \\ HOD Dept of Paediatrics, ${ }^{3}$ Dr.Rabindra Nath Das, Associate Professor, M.D. Microbiology, MRCP, FRCP, Dept. of Medicine, \\ ${ }^{4}$ Dr. Maninder Singh Dhaliwal, M.D. Paediatrics, Assistant Professor, Dept of Paediatrics, ${ }^{5}$ Dr. Kamal Subedi, Medical Officer. \\ Dept of Paediatrics. Manipal College of Medical Sciences (MCOMS), Pokhara, Nepal., MCOMS.
}

Address For Correspondence: Dr. Pradipta Kumar Swain.

E-mail: pkswain1@rediffmail.com; pk_swain@indiatimes.com

\begin{abstract}
Context: Neurocysticercosis is a endemic disease in Nepal causing social and financial burden on society and developmental problem in children. Aims: To determine the efficacy of albendazole plus oral prednisolone in children with 1 or 2 ring-enhancing lesions (by CT) on resolution of lesions and recurrence of seizure. Setting and Design: Randomized controlled open trial. Methods and Materials: Children with 1 or 2 ring-enhancing lesions $<20 \mathrm{~mm}$ in diameter on computed tomography scan, likely to have Neurocysticercosis, were assigned to treatment $\&$ control groups. Children assigned to the treatment group $(\mathrm{n}=50)$ were given $2.0 \mathrm{mg} / \mathrm{kg}$ per day prednisolone orally for 5 days plus $15 \mathrm{mg} / \mathrm{kg}$ per day albendazole on third day for 28 days. Anti epileptic drugs were given to both groups $\{$ including Control group $(\mathrm{n}=51)\}$. Statistical Analysis: The results were analysed with the use of Epi Info version 6.04 and Stata version; 7 software. Results: The lesions resolved completely or partially in more children in the treated group compared with the control group $(p=.04 \& p=0.03)$. The proportion of children who had seizures was significantly lower in the treated group compared with the control group at 6 months $(10 \%$ versus $33 \% ; \mathrm{p}=.006)$ and 12 months $(14 \%$ versus $38 \% ; \mathrm{p}=.003)$. Conclusion: Albendazole plus Prednisolone increased resolution of lesions on computed tomography scan and reduced the risk of subsequent recurrence of seizures among children with Neurocysticercosis.
\end{abstract}

Key words: Prednisolone, Albendazole, Neurocysticercosis and Children.

\section{Introduction}

In the developing world, Neurocysticercosis, infection of the central nervous system with Taenia solium larvae is the single most common cause of acquired epilepsy ${ }^{1}$. Inflammatory granulomas of the central nervous system are common in developing countries, where recent studies report that $26 \%$ to $72 \%$ of hitherto normal children with a first episode of seizure have a ring or disk enhancing lesion on computed tomography $(\mathrm{CT})^{2-8}$. The anticysticercal treatment of single enhancing CT lesions, thought to represent dying cysticerci and thus expected to resolve spontaneously, has been controversial. 7, 9, 10,11, 12., 13. Additionally, there is also concern that cysticidal therapy may lead to an enhanced inflammatory response caused by release of larval antigens that can precipitate seizures ${ }^{12,14,15}$. On the contrary, there is some experience that Cysticidal therapy may lead to faster resolution of lesions and better seizure control ${ }^{7}, 16,17,18,19$. Between the two randomized controlled trials that evaluated the efficacy of anticysticercal therapy in children with single enhancing lesions, one showed earlier resolution of CT lesions and lower seizure recurrence ${ }^{20}$ whereas the other reported no benefit ${ }^{21}$. We conducted this randomized, controlled, open trial to determine the effect of albendazole plus prednisolone in children with seizures and 1 or 2 ring-enhancing lesions on resolution of the lesion as well as seizure recurrence.

\section{Methods}

This study was undertaken from January 2004 to May 2007. All patients of either sex, 1year to 14 years of age, with seizures and 1 or 2 ring-enhancing lesions $<20 \mathrm{~mm}$ in diameter with or without perifocal oedema on CT scan at the Manipal Teaching Hospital, Pokhara, Nepal, were screened for selection in this study. Child and family characteristics and clinical data on type and frequency of seizures, anti-epileptic therapy, presence of interictal headache, vomiting, focal neurologic deficit, or any other neurologic symptoms were recorded on a prestructured questionnaire. Complete clinical assessment was done at the time of enrolment and each follow-up. The side effects of albendazole plus prednisolone treatment and its expected efficacy were explained to parents, and their agreement to let their children participate was obtained before enrolment.

A simple randomization scheme was used for allocation of patients to the treated or control groups. Random assignment code was concealed up to the time of allocation in sealed envelopes labelled with a unique patient number. These envelopes were opened sequentially after consent was obtained to enrol an eligible child. Children assigned to the treatment group were given $2 \mathrm{mg} / \mathrm{kg}$ /day oral prednisolone for 5 days in 3 to 4 divided doses and $15 \mathrm{mg} / \mathrm{kg}$ per day oral albendazole as a single daily dose at night for 28 days, 
starting on the third day of prednisolone. Children in the control group were not given prednisolone or albendazole.

Anti-epileptic therapy was given to both the study groups. If an anti-epileptic drug had been started before enrolment, it was continued in appropriate doses if seizures were controlled. Others were given Sodium Valproate in a dose of $15-25 \mathrm{mg} / \mathrm{kg}$ per day as twice a day dose. The dose was increased to $40 \mathrm{mg} / \mathrm{kg}$ per day if seizures recurred. None of the children required addition of a second anti-epileptic drug.

Children with evidence of tuberculosis by chest radiography, a positive Mantoux test, or a history of contact with a patient with tuberculosis were excluded. Children with intraocular cysts or with multiple lesions $(>2)$, disk or calcified lesions, Intraventricular cysts, or hydrocephalus on CT scan were also excluded from the study. Children with neurological deficit, signs of increase intracranial pressure $\&$ papiloedema were also excluded from the study.

\section{Follow-up and Outcome Variables}

A single radiologist blinded to treatment assignment and to the clinical outcome performed evaluation of CT lesions at baseline and 6-month follow-up scans. The site, type, size of lesion and degree of perifocal oedema were recorded, along with any change compared with the previous scan. The effect of therapy on the CT lesions was categorized as beneficial if the lesions disappeared, were reduced in size by $>50 \%$, or were calcified

All patients were evaluated 15 days after enrolment for side effects of albendazole plus prednisolone, which included seizures, headache, vomiting, and visual problems. Recording the missed doses since last visit monitored adherence to treatment.

Study children were evaluated at 6 and 12 months after enrolment to determine efficacy of treatment. Data on recurrence, frequency, and type of seizures were recorded. Seizure recurrence was assessed on the basis of history from parents at the follow-up visits. Follow up was done every monthly up to 6 months and then 3 monthly up to 12 months of enrolment.

\section{Statistical Analysis}

The results were analyzed with the use of Epi Info version 6.04 and Stata version;7 software (Stata Corp, College Station, Tex). The proportions of children who had recurrence of seizures and improvement in the CT lesions in the treatment group were compared with those in the control group. Difference in proportions and their $95 \%$ confidence intervals are presented.

\section{Results}

\section{Baseline characteristics}

110 patients, out of whom parents of 9 patients refused to participate, met eligibility criteria. The remaining 101 children were randomly assigned to treatment $(\mathrm{n}=50)$ and control groups $(\mathrm{n}=51)$. The number of children lost to follow-up was similar in the two study groups: $2(4 \%)$ and 6
Table 1: Baseline Characteristics Of Patients In The Treatment (Albendazole Plus Prednisolone) And Control Groups.

\begin{tabular}{|c|c|c|}
\hline Characteristics & $\begin{array}{l}\text { Treatment } \\
\text { Group }(50)\end{array}$ & $\begin{array}{c}\text { Control } \\
\text { Group }(51)\end{array}$ \\
\hline Mean age in month & 94 & 92 \\
\hline Males $(\%)$ & $27(54)$ & $28(55)$ \\
\hline \multicolumn{3}{|l|}{ Types of seizures $n(\%)$} \\
\hline Generalized (\%) & $11(22)$ & $10(20)$ \\
\hline Partial (\%) & $37(74)$ & $36(72)$ \\
\hline Multiple (\%) & $1(2)$ & $2(4)$ \\
\hline Partial to generalized seizure $(\%)$ & $1(2)$ & $2(4)$ \\
\hline Mean no. of seizure (SD) & $2.6(2.9)$ & $2.8(2.7)$ \\
\hline Valproate therapy $(\%)$ & $48(96)$ & $46(90)$ \\
\hline Headache $(\%)$ & $22(44)$ & $18(35)$ \\
\hline Vomiting $(\%)$ & $5(10)$ & $3(6)$ \\
\hline History of taking pork $(\%)$ & $30(60)$ & $28(55)$ \\
\hline \multicolumn{3}{|l|}{ Lesions on CT } \\
\hline Single $(\%)$ & $41(82)$ & $44(86)$ \\
\hline Double (\%) & $9(18)$ & $7(14)$ \\
\hline Right side (\%) & $28(56)$ & $24(47)$ \\
\hline Left side $(\%)$ & $22(44)$ & $27(53)$ \\
\hline Parietal lobe $(\%)$ & $34(68)$ & $31(61)$ \\
\hline Frontal lobe $(\%)$ & $13(26)$ & $16(31)$ \\
\hline Temporal lobe $(\%)$ & $2(4)$ & $3(6)$ \\
\hline Occipital lobe (\%) & $1(2)$ & $1(2)$ \\
\hline Abnormal EEG (\%) & $13(26)$ & $11(21.5)$ \\
\hline
\end{tabular}

(12\%) at 12 months follow-up. The two study groups were similar for most baseline characteristics (Table I) results for Neurocysticercosis. The majority $(84 \%)$ of enrolled children had a single lesion on CT scan, and most (97\%) had perifocal oedema. The characteristics of the lesion on CT scan were similar in both groups.

\section{Adverse effects during first two weeks of treatment}

In the 15 days' follow-up after enrolment, the proportion of children with headache, vomiting, or visual problems were not significantly different between the two study groups. There was a trend toward decrease in seizures during the initial period of treatment in the albendazole plus prednisolone group compared with the control group $(3.0 \%$ vs. $14.0 \% ; \mathrm{p}=.09)$.

\section{Efficacy of albendazole plus prednisolone treatment}

After the first CT scan, repeat CT scan at 6 months after enrolment could be obtained in 93 children (92.0\%), after a mean duration of 178 (SD 34) days in the treatment group and 166(SD 36) days in the control group. Changes in CT scans after 6 months of treatment is depicted in Table-2 with $\mathrm{p}$ value. Total resolution, Partial resolution, calcification and no changes in lesions in CT scan both in the control \& treatment group revealed significant difference in both total and partial resolution group only $(\mathrm{p}<0.05)$. 
Table 2: Comparison of Both the Control \& Cases After 6 Months \& 12 Months of Follow-Up.

\begin{tabular}{|c|c|c|c|c|}
\hline Characteristics & Treatment group $(48)$ & Control group(45) & $\begin{array}{c}\text { Difference in } \\
\text { proportions }(95 \% \mathrm{CI})\end{array}$ & $p$-value \\
\hline \multicolumn{5}{|l|}{ CT findings after 6 months } \\
\hline Complete resolution of lesion & $14(29 \%)$ & $9(20 \%)$ & $9 \%(3 \%$ to $27 \%)$ & 0.04 \\
\hline Partial resolution & $20(41.5 \%)$ & $7(15.5 \%)$ & $26 \%(9$ to $38 \%)$ & 0.03 \\
\hline Calcification of lesions & $4(8.2 \%)$ & $10(22.2 \%)$ & $-14 \%(-24 \%$ to $-6 \%)$ & 0.06 \\
\hline No changes in lesion & $10(20.8 \%)$ & $19(42.2 \%)$ & $-21 \%(-37 \%$ to- $19 \%)$ & 0.09 \\
\hline \multicolumn{5}{|l|}{ Incidence of seizure recurrences } \\
\hline 0-6 months post enrolment & $5(10 \%)$ & $15(33 \%)$ & $-23 \%(-35 \%$ to $-6 \%)$ & 0.006 \\
\hline $0-12$ months post enrolment & $7(14 \%)$ & $17(38 \%)$ & $-24 \%(-38 \%$ to $-3 \%$ & 0.003 \\
\hline
\end{tabular}

Worsening of findings in the scan, defined as appearance of new lesions, was not seen in any treatment or control group. During the 6-month post enrolment period, a significant reduction was observed in seizure recurrence, when only 5 $(10 \%)$ of children in the treatment group had any seizures compared with $17(33 \%)$ children in the control group ( $p$ $=0.006)$. The proportion of children who had a seizure in the 12 months' follow-up period after enrolment was also significantly lower in the treatment group $(14.0 \% \mathrm{vs} 38.0 \%$, $p=0.003)$.

Fig 1: CT Scan With Contrast in a Child Showing Racemose Type of Neurocysticercosis.Fig

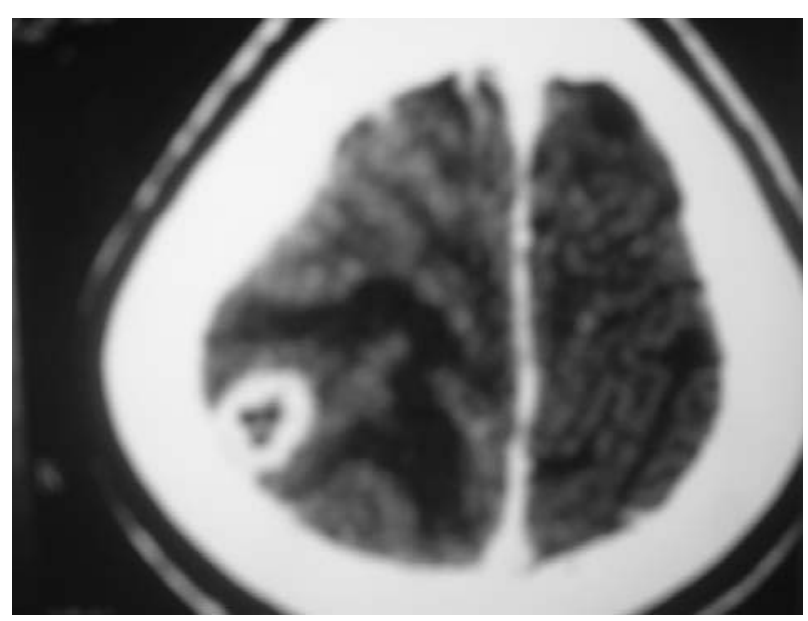

\section{Discussion}

The main findings of this study are that albendazole plus prednisolone significantly increased the complete or partial resolution of the $\mathrm{CT}$ lesion and reduced the risk of seizures during 12 months of follow-up in children who had seizures and 1 or 2 ring-enhancing lesions of Neurocysticercosis on CT scan. The other study conducted exclusively in children found cysticidal therapy to be beneficial in resolution of the lesion in children with single ring-enhancing lesions ${ }^{20}$, our findings are consistent with this study.

Patients have clinical symptoms rather than an abnormal CT scan, and therefore some contend that an assessment of clinical outcome is a better measure of efficacy of treatment.
As seizures are the most frequently occurring symptom, seizure recurrence may represent one clinical outcome that can be defined and quantified. After 12 months of follow-up in our study, a significantly higher proportion of patients in the control group had recurrence of seizures compared with the treated group $(38.0 \%$ versus $14.0 \% ; \mathrm{p}<0.05)$. The previous trial in children also reported a trend toward reduction in seizure recurrence $(31 \%$ in placebo vs. $13 \%$ in the treated group), but this difference was not statistically significant ${ }^{20}$. Garg RK et al also reported a decrease in seizure recurrences in childhood Neurocysticercosis having 1 to 2 ring enhancing lesions $(\mathrm{n}=12 \% \mathrm{vs} .=48 \%)$ in prednisolone treated group ${ }^{22}$.

Some previous reports cited adverse reactions such as increased severity of seizures, worsening of pre-existing intracranial hypertension and even death during the initial period of treatment ${ }^{17,20}$. However, we did not find higher incidence of seizures, headache, vomiting, or visual problems in the treated children during the initial twoweeks of therapy. One study from India also reported short-term prednisolone therapy helps in rapid resolution of solitary cysticercus granuloma in-patients with new-onset seizures and resolution of lesions is associated with improved seizurerelated prognosis, which was similar to our study ${ }^{23}$.

We do not believe that the lack of blinding of the treating physician or patient affected the results of this study, since one of our primary outcome variables lesion on CT scan-was evaluated by the radiologist, who was blinded to the treatment group and to clinical outcome.

\section{Conclusion}

In conclusion, albendazole plus prednisolone treatment in children with 1 or 2 ring-enhancing lesions on CT scan due to neurocysticercosis resulted in early resolution of CT lesions and less recurrence of seizures up to 12 months of follow-up. Multicenter studies with long-term follow-up are required to confirm these findings and determine the effect of cysticidal therapy on seizures beyond 12 months of therapy.

\section{Acknowledgement}

We are thankful to our Dean Prof. Dr. S.K. Dham for giving us his kind permission to conduct the study \& to publish this work. 


\section{References}

1. R.S. Wadia, C.N. Makhale, A.V. Kelkar and K.B. Grant, Focal Epilepsy In India With Special Reference To Lesions Showing Ring Or Disc Like Enhancement On Contrast Computed Tomography. J Neurol Neurosurg Psychiatry 50 (1987), pp. 1298-1301.

2. M. Medina, E. Rosas, F. Rubio-Donnadieu and J. Sotelo, Neurocysticercosis As The Main Cause Of Late Onset Epilepsy In Mexico. Arch Intern Med 150 (1990), pp. 325-327.

3. V. Kalra, A. Bagga and A. Sethi, Etiology Of Partial Seizures In Children: A Clinico-CT Study. In: S. Ohtabana and J. Roger, Editors, New Trends In Pediatric Epileptology (1991), pp. 129-135.

4. J.S. Chopra, I.M.S. Sawhney, N. Suresh, S. Pravhakar, U.K. Dhand and S. Suri, Vanishing CT Lesions In Epilepsy. J Neurol Sci 107 (1992), pp. 40-49.

5. H.H. Garcia, R. Gilman, M. Martinez, V.C. Tsang, J.B. Pilcher, G. Herrera et al., Cysticercosis As A Major Cause Of Epilepsy In Peru. Lancet 341 (1993), pp. 197 200

6. R.K. Garg and D. Nag, Single Ring Or Disc Enhancing Computed Tomographic Lesion In Indian Children And Adolescents After First Seizure [letter]. Arch Pediatr Adolesc Med 157 (1997), pp. 632-634.

7. A. Carpio, A. Escobar and W.A. Hauser, Cysticercosis And Epilepsy: A Critical Review. Epilepsia 39 (1998), pp. 1025-1040.

8. P. Singhi, M. Ray, S. Singhi and N. Khandelwal, Clinical Spectrum Of 500 Children With Neurocysticercosis And Response To Albendazole Therapy. J Child Neurol 15 (2000), pp. 207-213.

9. R. Salinas and K. Prasad, Drugs For Treating Neurocysticercosis (Tapeworm Infection Of The Brain) (Cochrane Review). In: The Cochrane Library, Issue 2 (4th ed ed.), Update Software, Oxford (2001).

10. M.V. Padma, M. Behari, N.K. Misra and G.K. Ahuja, Albendazole In Neurocysticercosis. Natl Med J India 8 (1995), pp. 25-28.

11. R.K. Garg, Drug Treatment Of Neurocysticercosis. Natl Med J India 10 (1997), pp. 173-177.

12. B. Miller, V. Grinnell, M. Goldberg and D. Heiner, Spontaneous Radiographic Disappearance Of Cerebral Cysticercosis: Three Cases. Neurology 33 (1983), pp. 1377-1379.
13. R.K. Garg, M.K. Singh and S. Misra, Single-Enhancing CT Lesions In Indian Patients With Seizures: A Review. Epilepsy Res 38 (2000), pp. 91-104.

14. O.M. Takayanagui and E. Jardim, Therapy For Neurocysticercosis: Comparison Between Albendazole And Praziquantel. Arch Neurol 49 (1992), pp. 290294.

15. O.H. Del Brutto, Prognostic Factors For Seizure Recurrence After Withdrawal Of Anti-Epileptic Drugs In Patients With Neurocysticercosis. Neurology 44 (1994), pp. 1706-1709.

16. O.H. Del Brutto, Neurocysticercosis In Children, Clinical And Radiological Analysis And Prognostic Factors In 54 Patients. Rev Neurol 25 (1997), pp. 16811684.

17. V. Vazquez and J. Sotelo, The Course Of Seizures After Treatment For Cerebral Cysticercosis. N Engl J Med 327 (1992), pp. 696-701.

18. M.T. Medina, P. Genton, M.C. Montoya, S. Cordova, C. Dravet and J. Sotelo, Effect Of Anticysticercal Treatment On The Prognosis Of Epilepsy In Neurocysticercosis: A Pilot Trial. Epilepsia 34 (1993), pp. 1024-1027.

19. I.C. Santos, E. Kobayashi, T.M. Cardoso, C.A. Guerreiro and F. Cendes, Cysticidal Therapy: Impact On Seizure Control In Epilepsy Associated With Neurocysticercosis. Arq Neuropsiquiatr 58 (2000), pp. 1014-1020.

20. A.K. Baranwal, P.D. Singhi, N. Khandelwal and S.C. Singhi, Albendazole Therapy In Children With Focal Seizures And Single Small Enhancing Computerised Tomographic Lesions: A Randomised, PlaceboControlled, Double Blind Trial. Pediatr Infect Dis J 17 (1998), pp. 696-700.

21. M.V. Padma, M. Behari, N.K. Misra and G.K. Ahuja, Albendazole In Single CT Ring Lesions In Epilepsy. Neurology 44 (1994), pp. 1344-1346.

22. Garg RK, Potluri N, Kar AM, Singh MK, Shukla R, Agrawal A, Verma R., Short Course Of Prednisolone In Patients With Solitary Cysticercus Granuloma: A Double Blind Placebo Controlled Study. J Infect. 2006 Jul;53(1):65-69.

23. Mall RK, Agarwal A, Garg RK, Kar AM, Shukla R. Short Course Of Prednisolone In Indian Patients With Solitary Cysticercus Granuloma And New-Onset Seizures. Epilepsia. 2003 Nov;44(11):1397-401. 